\title{
Aplasia cutis congenita-intestinal lymphangiectasia syndrome
}

INSERM

\section{Source}

INSERM. (1999). Orphanet: an online rare disease and orphan drug data base. Aplasia cutis congenita-intestinal lymphangiectasia syndrome. ORPHA:1116

Aplasia cutis congenita-intestinal lymphangiectasia syndrome is an extremely rare association syndrome, described in only two brothers to date (one of which died at 2 months of age), characterized by aplasia cutis congenita of the vertex and generalized edema (as well as hypoproteinemia and lymphopenia) due to intestinal lymphangiectasia. There have been no further descriptions in the literature since 1985. 